\title{
Myxolipoma in the tongue - A clinical case report and review of the literature
}

\author{
Shigehiro Ono ${ }^{1 \dagger}$, Majeed Rana ${ }^{3^{*}+}$, Masaaki Takechi ${ }^{1}$, Ikuko Ogawa ${ }^{2}$, Gaku Okui ${ }^{1}$, Yoshitsugu Mitani ${ }^{1}$, \\ Nils-Claudius Gellrich ${ }^{3}$ and Nobuyuki Kamata ${ }^{1}$
}

\begin{abstract}
In this article, we present our experience with a case of myxolipoma of the tongue.

Lipoma is a mesenchymal benign tumor occurring with relatively high frequency. However, myxolipoma, one of the histological variant of lipoma characterized by mature adipose tissue and abundant mucoid substances, in the oral cavity is quite rare.

The patient was a 52-year-old man who noticed a painless mass on the left border of tongue about 2 years ago. The lesion was noted at a complete medical checkup, and the patient was admitted to our institution for detailed examination. The mass was a palpable, soft and elastic nodule, $15 \mathrm{~mm}$ in diameter, covered with normal mucosa in the left inferior aspect of the tongue. The border of the tumor was well-defined, and computed tomography (CT) revealed a fat density within the mass. On the basis of these finding, the tumor was clinically diagnosed as lipoma and was excised under general anesthesia. Histopathologically, the tumor was a well-defined lobulated mass surrounded by a thin fibrous capsule within the muscle of the tongue. The tumor was diagnosed as myxolipoma because it was consisted of solid proliferation of mature adipocytes replaced by abundant mucoid substances. The post operative course was uneventful, and there was no evidence of recurrence 4 years after surgery,
\end{abstract}

Keywords: Myxolipoma, Tongue benign tumor, Lipoma

\section{Background}

Lipoma is the most common neoplasms arising from fat tissue. They are usually having the character of slowgrowing, soft and silent masses. Angiolipoma, spindle cell lipoma, myelolipoma, chondorolipoma and myolipoma are some histologic variants of lipomas. Myxolipoma is a lipoma admixed with abundant mucoid substances and is considered to be a lipoma with a high degree of myxoid change [1,2].

However mixolipoma is infrequently observed as neoplasm in the trunk, it rarely occurs in oral region. Only fourteen cases of involving the oral regions, including tougue, buccal mucosa, and lowerlip have been reported in the English literature [1-4]. The incidence rate in the tongue, the buccal mucosa and the lower lip was almost

\footnotetext{
* Correspondence: rana.majeed@mh-hannover.de

† Contributed equally

${ }^{3}$ Department of Cranio-Maxillo-Facial Surgery, Hannover Medical School, Germany

Full list of author information is available at the end of the article
}

equal. In this report, the authors present the clinical and histological features of mixolipoma excised from the tongue with review of the literature.

\section{Case report}

A 52-year-old man was referred for a painless mass of the left lateral tongue. He had been aware of the mass for about 2 years previously, but had not sought medical attention. Three months before his first visit, he was found to have this mass at a general checkup. There is nothing special in his previous medical or familial history.

Intraoral examination revealed a solitary, $15 \times 15 \mathrm{~mm}$ sized mass on the left border of the tongue (Figure 1). The mass covered with normal mucous membrane was elastic, soft, and movable. Its circumference was not indurated, and the patient felt no tenderness or spontaneous pain. External to the oral cavity, his face was symmetrical, and there were no swollen lymph nodes or tenderness in the neck.

\section{() Biomed Central}




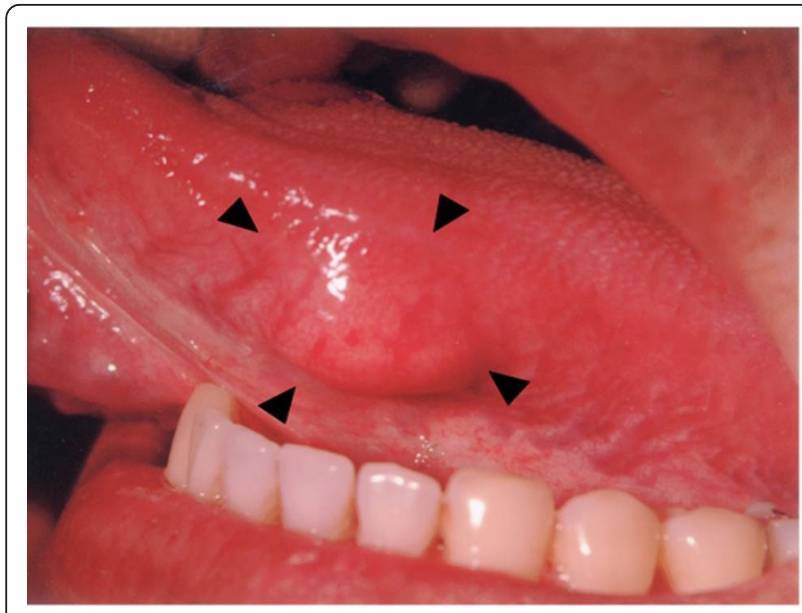

Figure 1 Clinical photograph of the lesion on the margin of the tongue (anterior surface, $15 \times 15 \mathrm{~mm}$ ).

CT showed a $15 \mathrm{~mm}$-sized well-defined lesion with fat concentration inside on the left border of the tongue (Figure 2). Echography showed a $15 \times 13 \times 8 \mathrm{~mm}$ dense highly echoic tumor (Figure 3).

On the basis of these findings, the tumor was clinically diagnosed as a benign lingual tumor (lipoma) and was

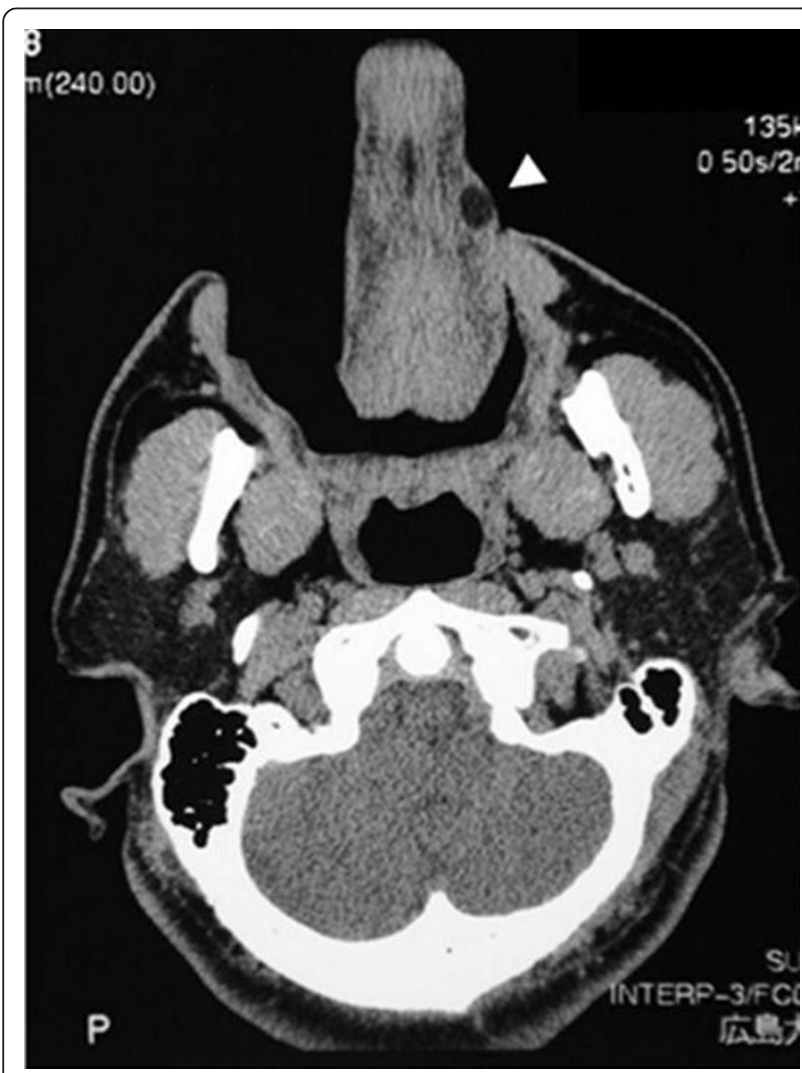

Figure $2 \mathrm{CT}$ revealed a mass at the left side and the edge of the tongue.

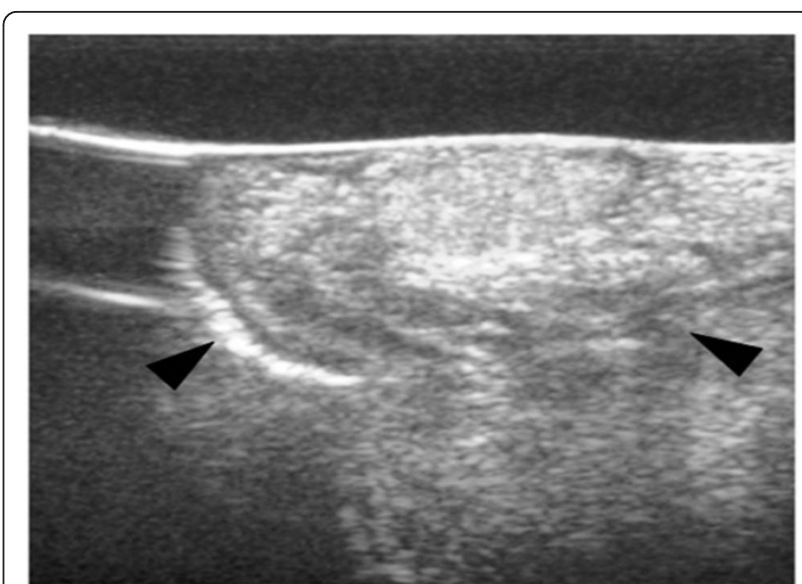

Figure 3 Echography showed a $15 \times 13 \times 8 \mathrm{~mm}$ dense highly echoic tumor

excised under general anesthesia. The mass was well demarcated and was easily separated from the surrounding tissue.

The excised mass was elastic-soft and yellowish-white and showed lobulation on its cut surface (Figure 4, 5). Histopathologically, the tumor was encapsulated and lobulated by a thin fibrous tissue (Figure 6). It was composed of solid proliferation of mature adipocytes admixed with abundant mucoid substances positively stained with alcian blue (Figs. 7, 8, 9). The myxoid areas contained scattered short-spindle smaller cells (Figure 8). Lipoblasts were not present and cellular atypia and mitotic figures were not found. A diffuse plexiform capillary network was not prominent.

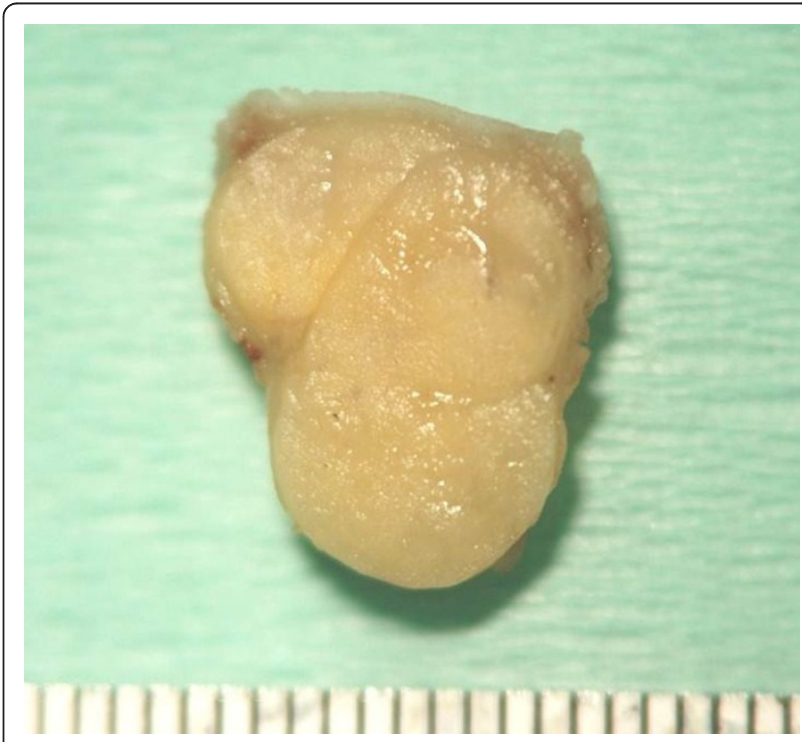

Figure 4 The surgical specimen measured $1.4 \mathrm{~cm}$ in its greatest dimension. 


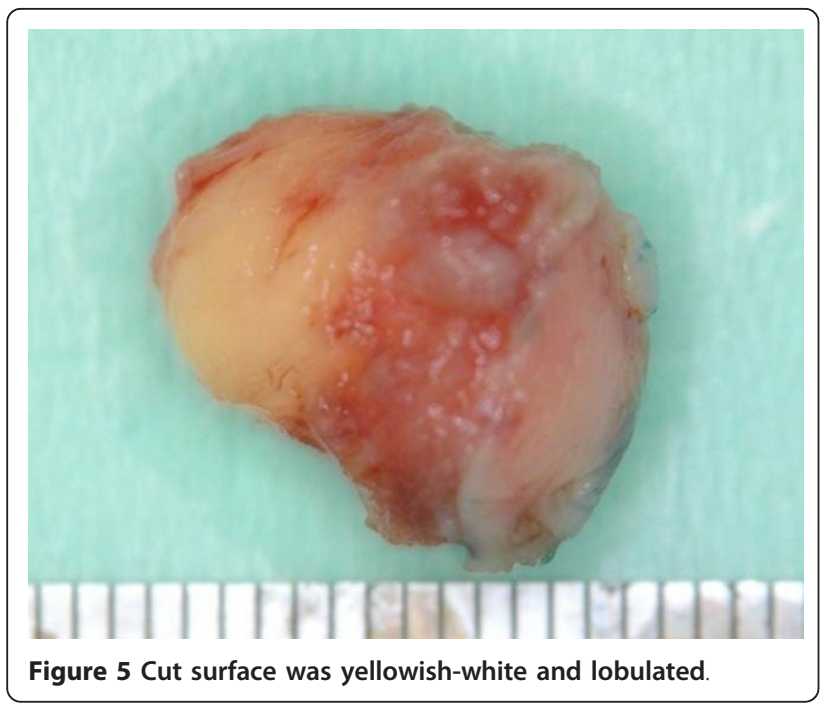

Immunohistochemically, the tumor cell expressed S-100 protein and were negative for CD34 and bcl-2 (Figure $10,11,12)$. Final diagnosis of myxolipoma was made.

Postoperatively, there has been no lingual dysfunction or any particular problems. The post operative course was uneventful, and there was no evidence of recurrence 4 years after surgery.

\section{Discussion}

Although lipoma represents the most common mesenchymal tumor, its occurrence in the oral and maxillofacial regions is not frequent. As lipomas are occasionally altered by an admixture of other mesenchymal elements, the microscopic variants have been described, including fibrolipoma, sclerotic lipoma, chondrolipoma, osteolipoma, myolipoma and angiomyxolipoma. Myxolipoma is a lipoma admixed with abundant

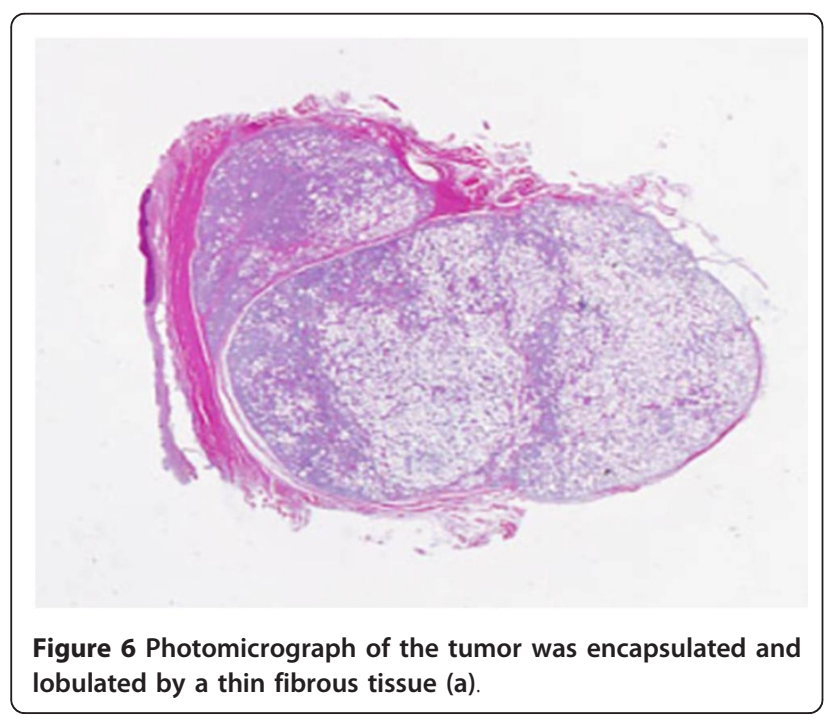

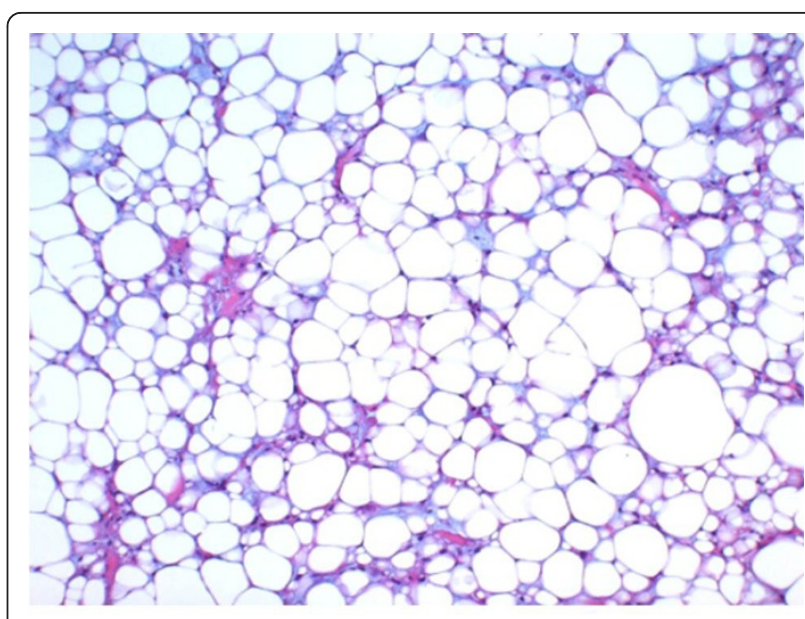

Figure 7 It was composed of solid proliferation of mature adipocytes.

mucoid substances and is considered to be a lipoma with a high degree of myxoid change[1,2]. The mucoid substances are positively stained with alcian blue and are digested by hyaluronidase. Only 14 cases of this variant involving the oral regions have been reported in the English literature (Table 1). Ages ranged from 30 to 70 years The incidence rate in the tongue, the buccal mucosa and the lower lip was almost equal.

Myxolipoma has to be distinguished from benign and malingnant lipomatous tumors with abundant mucoid substances, such as chondroidlipoma, spindle cell lipoma with myxoid changes and myxoid liposarcoma. Chondroidlipoma shows nest-like or cord-like growth of lipoblasts, and its mucoid matrix is resistant to hyaluronidase[5]. Spindle cell lipoma with myxoid change includes CD34-positive and bcl-2-positive

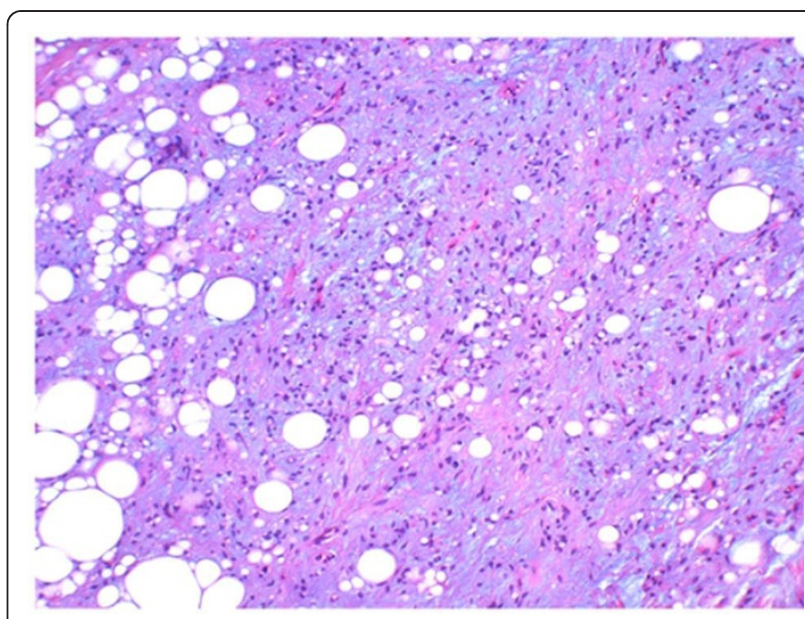

Figure 8 The solid proliferation replaced by abundant basophilic mucoid substances containing short-spindle smaller cells. 


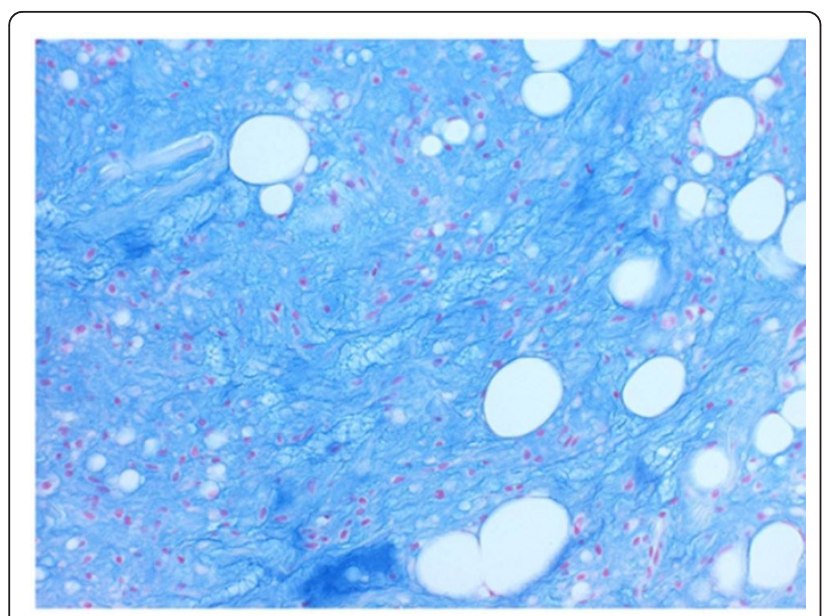

Figure 9 The matrix showed strong positivity with alcian-blue.

spindle cells, which develop on endocapillary cells[6]. Myxoid liposarcoma is a malignant tumor that includes atypical lipoblasts and is characterized by a rich capillary network [7]. Clinical and histopathological findings of the present case are summarized as follows. The tumor was encapsulated and lobulated by a thin fibrous tissue and was composed of a mixture of a solid growth of mature adipocytes and areas rich in mucoid substances posotively stained with alcian-blue and digestable by hyaluronidase. Immunohistochemical analysis showed that short spindle cells in mucoid substances in addition to mature adipocytes are positive for $\mathrm{S}-100$ and negative for CD34 and bcl-2 [6]. There were no malignant features including lipoblast and an abundant capillary network [7]. Therefore, we finally diagnosed the present tumor as myxolipoma.

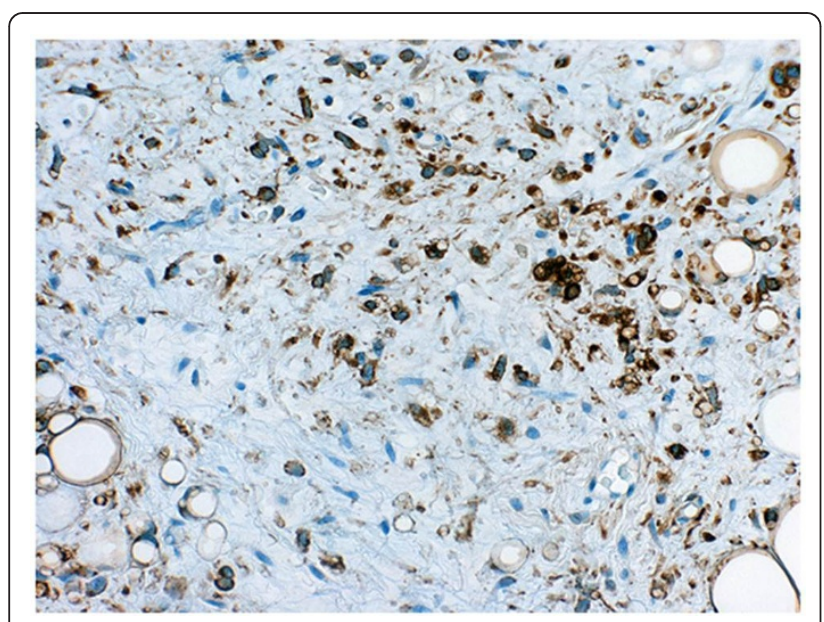

Figure $10 \mathrm{Immunohistochemical} \mathrm{staining} \mathrm{patterns.} \mathrm{The} \mathrm{mature}$ adipocytes and the shirt-spindle smaller cells were strongly positive for S-100 protein

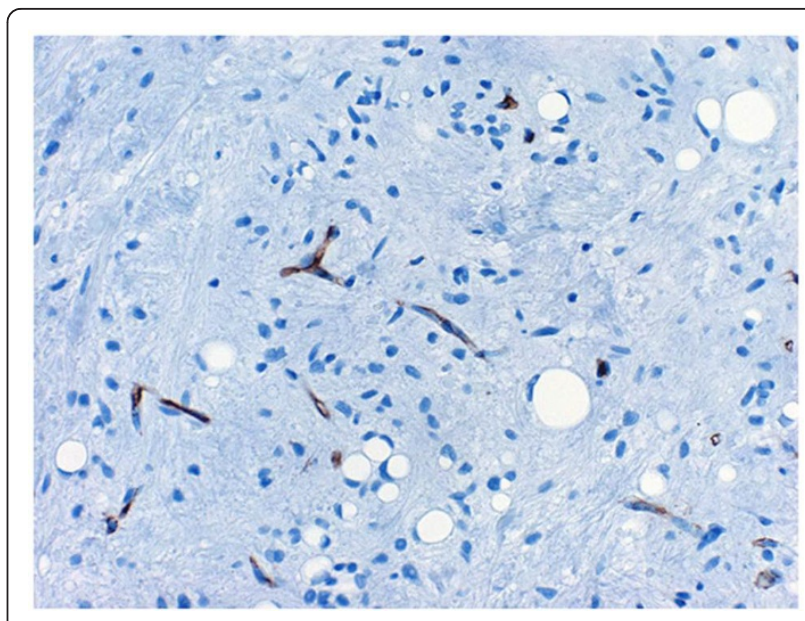

Figure 11 The mature adipocytes and the shirt-spindle smaller cells were negative for CD34. And endothelial cells were positive for CD34.

As for treatment, surgical excision becomes first choice [1-4]. There have been no reports of relapse in any of the reports of myxolipma occurring in the entire body, whether within the oral cavity, on the larynx [8], on the thigh [9], on the skin [10], or in the cervicomediastinum [11]; thus, we consider myxolipoma to carry a relatively benign prognosis. In the present case, for the 4 postoperative years until the present, the patient has suffered no relapse, and he is making satisfactory progress.

\section{Consent statement}

Written informed consent was obtained from the patient for publication of this case report and accompanying

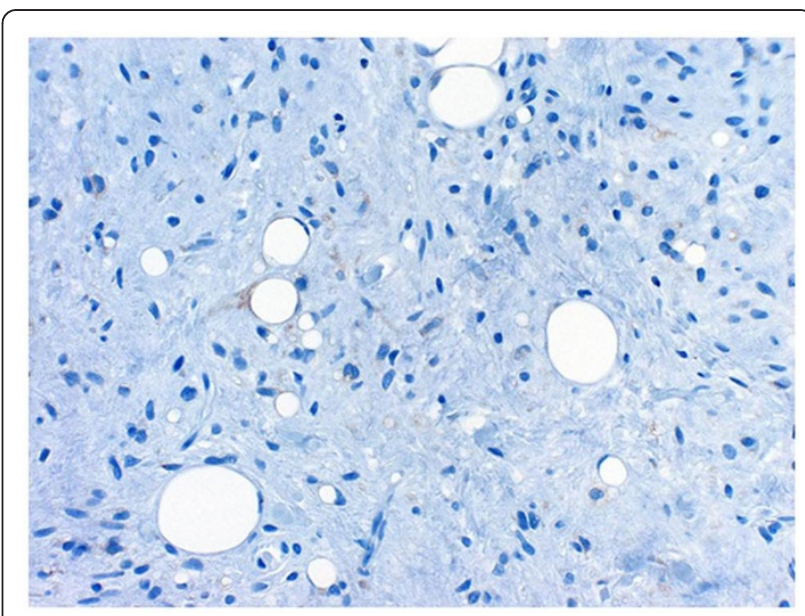

Figure 12 Immunohistochemical staining patterns showed that the mature adipocytes and the shirt-spindle smaller cells were negative for bcl-2 
Table 1 Clinical feature of reported patients with Myxolipoma in oral cavity

\begin{tabular}{|c|c|c|c|c|c|}
\hline \multirow[t]{2}{*}{ Patient's ID } & \multicolumn{5}{|c|}{ Clinical feature } \\
\hline & age/sex & site & treatment & progress & author \\
\hline 1 & 52 male & tongue & resection & unknown & Auband JR[1] \\
\hline 2 & 70 female & tongue & resection & no relapse & Chen[2] \\
\hline 3 & 42 male & tongue & resection & no relapse & \\
\hline 4 & 30 male & buccal mucosa & resection & no relapse & \\
\hline 5 & 57 male & buccal mucosa & resection & no relapse & \\
\hline 6 & unknown & buccal mucosa & resection & no relapse & Said-Al-Naief N[3] \\
\hline 7 & unknown & tongue & resection & no relapse & \\
\hline 8 & unknown & tongue & resection & no relapse & \\
\hline 9 & unknown & lower lip & resection & no relapse & \\
\hline 10 & unknown & lower lip & resection & no relapse & \\
\hline 11 & unknown & lower lip & resection & no relapse & \\
\hline 12 & unknown & lower lip & resection & no relapse & \\
\hline 13 & unknown & gingiva & resection & no relapse & \\
\hline 14 & 55 male & buccal mucosa & resection & no relapse & Studart-Soares EC[4] \\
\hline
\end{tabular}

images. A copy of the written consent is available for review by the Editor-in-Chief of this journal.

\section{Funding}

The article processing charges are funded by the Deutsche Forschungsgemeinschaft (DFG), "Open Access Publizieren".

\section{Author details}

${ }^{1}$ Department of Oral and Maxillofacial Surgery, Division of CervicoGnathostomatology, Graduate School of Biomedical Sciences, Hiroshima University, Japan. ${ }^{2}$ Center of Oral Clinical Examination, Hiroshima University Hospital, Kasumi 1-2-3, Minami-ku, Hiroshima, Japan. ${ }^{3}$ Department of CranioMaxillo-Facial Surgery, Hannover Medical School, Germany.

\section{Authors' contributions}

SO, MR, MT, IO, GO, YM, NCG and NK conceived of the study and participated in its design and coordination. SO and MR drafted the manuscript and contributed equally to this work. MR, NCG and NK were involved in revising the manuscript. All authors read and approved the final manuscript.

\section{Competing interests}

The authors declare that they have no competing interests.

Received: 4 December 2011 Accepted: 20 December 2011

Published: 20 December 2011

\section{References}

1. Ausband JR, Harrill JA, Pautler EE: Myxolipoma of the base of the tongue; report of a case. Ann Otol Rhinol Laryngol 1953, 62:1039.

2. Chen SY, Fantasia JE, Miller AS: Myxoid lipoma of oral soft tissue. A clinical and ultrastructural study. Oral Surg Oral Med Oral Pathol 1984, 57:300.

3. Said-Al-Naief N, Zahurullah FR, Sciubba JJ: Oral spindle cell lipoma. Ann Diagn Pathol 2001, 5:207.

4. Studart-Soares EC, Gurgel-Costa FW, Bitu-Sousa F, Alves AP, Osterne RL: Oral lipomas in a Brazilian population: A 10-year study and analysis of 450 cases reported in the literature. Med Oral Patol Oral Cir Bucal 2010.

5. Darling MR, Daley TD: Intraoral chondroid lipoma: a case report and immunohistochemical investigation. Oral Surg Oral Med Oral Pathol Oral Radiol Endod 2005, 99:331.
6. Imai T, Michizawa M, Shimizu H, Yamamoto N, Yura Y: Bilateral multiple spindle cell lipomas of the tongue. Oral Surg Oral Med Oral Pathol Oral Radiol Endod 2008, 106:264.

7. Fanburg-Smith JC, Furlong MA, Childers EL: Liposarcoma of the oral and salivary gland region: a clinicopathologic study of 18 cases with emphasis on specific sites, morphologic subtypes, and clinical outcome. Mod Pathol 2002, 15:1020.

8. Singhal SK, Virk RS, Mohan H, Palta S, Dass A: Myxolipoma of the epiglottis in an adult: a case report. Ear Nose Throat J 2005, 84:728, 730, 734.

9. Tokumaru S, Kudo S, Mihara M, Matsuo Y, Takeuchi T, Koda H, Tokunaga O: Myxolipoma mimicking a cystic tumor. Skeletal Radiol 1996, 25:573.

10. Cardot-Leccia N, Italiano A, Haudebourg J, Attias R, Amato D, Pedeutour F, Perrin C: Cutaneous myxolipoma with apocrine glandular differentiation: description of a new clinicopathological variant with chromosome $6 \mathrm{p} 21$ rearrangement. Histopathology 2008, 53:361.

11. Kitami A, Suzuki T: A case report of cervicomediastinal lipoma. Nippon Kyobu Geka Gakkai Zasshi 1997, 45:624.

doi:10.1186/1758-3284-3-50

Cite this article as: Ono et al:: Myxolipoma in the tongue - A clinical case report and review of the literature. Head \& Neck Oncology 2011 3:50.

\section{Submit your next manuscript to BioMed Central and take full advantage of:}

- Convenient online submission

- Thorough peer review

- No space constraints or color figure charges

- Immediate publication on acceptance

- Inclusion in PubMed, CAS, Scopus and Google Scholar

- Research which is freely available for redistribution

Submit your manuscript at www.biomedcentral.com/submit
C Biomed Central 